and is in qualitative agreement with the observations discussed in the first paragraph. If $I$ is small, $y$ becomes independent of temperature, while if $P$ is small $y$ remains a function of temperature. The stoichiometric equations from which we have derived (2) and (3) are in agreement with the majority of observations on rates of photosynthesis. A bimolecular Blackman reaction is involved, instead of the monomolecular one proposed by Baly and Morgan, but their statement that the Blackman reaction is monomolecular appears to be without substantial support.

California Institute of Technology,

Robert EMERSON. LOWELL GREEN. Pasadena, California. June 7.

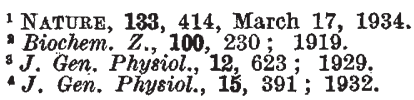

\section{Action of Phenyl Isocyanate on Insulin}

During the past three years, we have been investigating the properties of proteins which have been treated with phenyl isocyanates ${ }^{1}$. This reaction is of special value for the introduction of new groups into proteins, since it is rapid and can be carried out in neutral or faintly alkaline solution $(p H$ 7-8) and at relatively low temperatures $\left(5^{\circ}-8^{\circ} \mathrm{C}\right.$.).

The new protein compounds produced by this reaction have been studied by chemical and immunological methods, and these investigations show that phenyl isocyanate appears to react only with the free amino-groups of the protein. These free groups, from the chemical evidence of other authors and from the immunological evidence which we have presented, appear to be the $\varepsilon$-amino-groups of the lysine molecules.

In addition to the application of this reaction to some problems of immunological chemistry, it was thought desirable to make use of it for other purposes, and with this object in view we have studied the action of phenyl and $p$-bromophenyl isocyanates on insulin. (For a generous supply of insulin for this work we are indebted to Messrs. Boots Pure Drug Co., Ltd., Nottingham.) In particular, it was hoped that this investigation might yield useful information about the active groups of insulin, a problem which has received much attention during the past few years. In a very recent review of the chemistry of insulin by Jensen and Evans ${ }^{2}$, mention is made of some unpublished investigations by Jensen, Evans and Schock on the treatment of insulin with phenyl isocyanate. In view of this, it is of interest to record our own observations and to give a brief outline of the conclusions which we can draw from our previous chemical and immunological studies.

Treatment with phenyl or $p$-bromophenyl isocyanate rapidly causes complete or almost complete destruction of the activity of insulin. This inactivation is very rapid and is practically complete in 10 minutes at $5^{\circ}-8^{\circ} \mathrm{C}$. From our previous work on similar compounds, we can conclude that the isocyanate reacts with the free amino-groups of the insulin, and not to any significant extent, under the conditions of our experiments, with the hydroxyl groups of the tyrosine. Insulin appears to contain free amino-groups in addition to those of the lysine molecules, since a value of 1.00 per cent ${ }^{3}$ has been given for the amino-N of an insulin of potency 25 units per mgm., but insulin contains only 2 per cent of lysine 4 .

Preparations of $p$-bromophenylureido insulin which we have made have been found to contain $4 \cdot 8,5 \cdot 5$ and 5.0 per cent of bromine, and the theoretical value for complete reaction with all the free aminogroups is $5 \cdot 0$ per cent. Thus phenyl and $p$-bromophenyl isocyanates probably react with all the free amino-groups, including the $\varepsilon$-amino-groups of the lysine molecules. The basic groups of insulin appear, therefore, to be important for the physiological activity of insulin, a view which was tentatively suggested by Jensen ${ }^{5}$ in 1932.

S. J. Hopkins.

Department of Physiology,

A. Wormatl.

University of Leeds. July 11.

${ }^{1}$ Hopkins, S. J., and Wormall, A., Biochem. J., 27, 740 and 1706; 1933. 28, 228; 1934 .

Jensen, H., and Evans, E. A., Physiol. Rev., 14, 188; 1934

s Freudenberg, K., Dirscherl, W., and Eyer, H., Z. physiol. Chem. 202, $128 ; 1931$.

¿Jensen, H., and Wintersteiner, O., J. Biol. Chem., 98, 281 ; 1932.

- Jensen, H., Science, 75, 614; 1932 .

\section{Hive-Bees do not necessarily Sacrifice their Lives} when they Sting

MY scepticism regarding the frequent statement, for example, Bischoff ${ }^{1}$, that worker bees (Apis mellifica) cannot withdraw their barbed sting, and thus invariably die when they have stung, was first aroused by observing a raid by wasps (Vespa germanica) on a hive in Essex, in September 1926.

In one case a wasp made a bold entrance by the doorway, was met by a bee and vigorously repulsed. It entered again, and emerged at once, struggling with a bee, which eventually succeeded in throwing it to the ground. The bee seemed somewhat exhausted; but it recovered completely. The wasp fell helpless, and died a few minutes later.

Experiments with bees showed that, when induced to sting a handkerchief, some of them, perhaps a third, finally get the sting into a position from which they cannot extricate it, the whole gland and vesicle tearing out in their struggles. But many penetrating stabs are followed by successful withdrawal.

Eight insects were killed by making hive-bees sting them. These were muscid maggots and flies, chiefly Calliphora, a small acridiid grasshopper, and an Eristalis. Some died in a few minutes. All were dead within twenty-two hours. A frog was stung several times, the frog hopping away on one occasion with the bee hanging by its sting. The bee succeeded in withdrawing and re-stowing it, and appeared none the worse. I was stung on the thumb, and perhaps because it was unexpected and I acted more violently than our other subjects, the sting was left in the wound. In all the other cases, however, even when the same bee stung several times, the bee recovered and re-stowed its sting none the worse. There thus seems little ground for the belief that worker bees sacrifice themselves when stinging other insects, or that they are any more handicapped than wasps in defending their nests from such enemies, or that they can sting only once.

Imperial College of Tropical Agriculture, J. G. MYers. Trinidad.

I Bischoff, H., "Biologie der Hymenopteren", Berlin, p. 548. 